\title{
Helicobacter pylori outer membrane vesicles involvement in the infection development and Helicobacter pylori-related diseases
}

\author{
Magdalena Chmiela, Natalia Walczak and Karolina Rudnicka * (1)
}

\begin{abstract}
Helicobacter pylori - (H. pylori) play a role in the pathogenesis of gastritis, gastric and duodenal ulcers as well as gastric cancer. A possible involvement of outer membrane vesicles (OMVs) produced by H. pylori in the distribution of bacterial antigens through the gastric epithelial barrier and their role in the development of local and systemic host inflammatory and immune responses has been suggested. OMVs contain various biologically active compounds, which internalize into host cells affecting signaling pathways and promoting apoptosis of gastric epithelial and immunocompetent cells. OMVs-associated $\mathrm{H}$. pylori virulence factors may strengthen or downregulate the immune responses leading to disease development. This review describes the biological importance of $\mathrm{H}$. pylori OMVs and their role in the course of $\mathrm{H}$. pylori infections, as well as $\mathrm{H}$. pylori related local and systemic effects.
\end{abstract}

Keywords: Helicobacter pylori, outer membrane vesicles, virulence factor, inflammation, gastritis

\section{Introduction}

The pathogenicity of Helicobacter pylori

Helicobacter pylori (H. pylori) are Gram-negative microaerophilic, spiral-shaped bacteria that belong to the $\varepsilon$ subdivision of the Proteobacteria, order Campylobacterales, family Helicobacteriaceae. Due to ability to adhere to gastric epithelium or internalize inside the cells they colonize human gastric mucosa, and cause gastritis, gastric ulcers and even cancers, or even recently considered development of extragastric diseases [1-5]. The pathogenicity of $H$. pylori and the ability to cause various diseases depend on the high genomic variability of these bacteria [6].

The prevalence of $H$. pylori infections is associated with a geographical region or living conditions. Moreover the demographic flux of human populations induce the occurrence of new H. pylori genetic variants [7-14].

These bacteria are well adapted to the harsh environment of the gastric niche due to motility, urease production, variability of adhesins, different effector molecules, and the Lewis (Le) blood group antigens ( $\mathrm{Le}^{\mathrm{x}}$ and $\mathrm{Le}^{\mathrm{y}}$ ) expression,

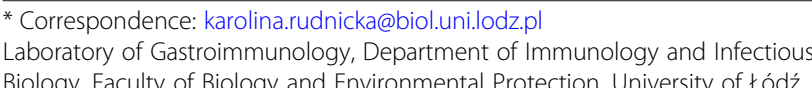

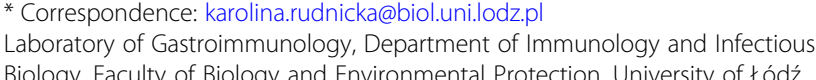

* Correspondence: karolina.rudnicka@biol.uni.lodz.pl
Laboratory of Gastroimmunology, Department of Immunology and Infectious
Biology, Faculty of Biology and Environmental Protection, University of Łódź, Banacha 12/16, 90-237 Łódź, Poland
}

(c) The Author(s). 2018 Open Access This article is distributed under the terms of the Creative Commons Attribution 4.0 International License (http://creativecommons.org/licenses/by/4.0/), which permits unrestricted use, distribution, and reproduction in any medium, provided you give appropriate credit to the original author(s) and the source, provide a link to the Creative Commons license, and indicate if changes were made. The Creative Commons Public Domain Dedication waiver (http://creativecommons.org/publicdomain/zero/1.0/) applies to the data made available in this article, unless otherwise stated. $[2,3,6,15,16]$. During the acute phase of colonization $H$. pylori resist the oxidative stress caused by excessive inflammatory response and in the chronic phase of infection, these bacteria downregulate the host immune responses driving the immunity towards tolerance rather than to a protective response [17-22]. Recently, it was shown that $H$. pylori replicate in murine bone marrow derived dendritic cells and on this way can affect immune responses mediated by these population of antigen presenting cells [23].

H. pylori virulence factors include cell-bound components, externally secreted molecules and antigens that need to be introduced to a host cell by the type IV secretion system (T4SS) such as cytotoxin-associated gene A (CagA) protein [20, 24-26]. However, similarly to other Gram-negative bacteria, $H$. pylori also produce outer membrane vesicles (OMVs) that contain various virulence factors and this strategy supports the survival of these bacteria in the gastric mucosa $[27,28]$. The studies on specific H. pylori compounds delivered by OMVs and on their role in the pathogenicity of these bacteria are ongoing. 


\section{General aspects of bacterial OMVs}

\section{Mechanism and conditions of bacterial vesiculation}

Outer membrane vesicles are defined as 20-300 nm blebs, which are naturally secreted by Gram-negative bacteria mainly during their logarithmic phase of growth although, Gram-positive bacteria also form the extracellular particles [29-34]. The models of OMVs biogenesis include: accumulation of peptidoglycan particles in the periplasm, which causes a turgor pressure; arising vesiculation in the relaxed cell wall-outer membrane regions as well as anionic repulsion and destabilization of outer membrane [35-38]. Recently, a novel mechanism of vesiculation has been proposed. It involves a VacJ/Yrb ABC (ATP-binding cassette) system - a potential phospholipid transporter engaged in phospholipid accumulation in the outer membrane [39]. OMVs produced by individual bacteria as well as those remaining in biofilms contain mainly periplasmic proteins, outer membrane proteins (OMPs) as well as lipids. In addition, some OMPs carry an extracellular DNA (eDNA), which plays a role in their aggregation during biofilm formation $[32,40]$. Some bacterial components do not remain within OMVs and others like heat-labile enterotoxins of enterotoxigenic Escherichia coli (ETEC) and aminopeptidase of Pseudomonas aeruginosa are elevated in vesicles, when compared to their expression in whole bacteria [35]. The genes specific for all strains that are responsible for the maintenance of the cell membrane organization and vesicle formation are localized within the tol-pal cluster [41].

The process of vesiculation is influenced by stress conditions such as increased temperature or the lack of nutrients. This phenomenon is genetically regulated and determines the interaction of the pathogen with host tissues and proteolytic enzymes, which was proved by showing the presence of bleb-like evaginations on the surface of Pseudomonas fragi observed within the damaged muscles of pigs exposed to these bacteria [42-44].

\section{The immunomodulatory potential of bacterial OMVs}

Previously, it was thought that OMVs promote survival of nonpathogenic species, while in pathogenic species enhance their virulence, the ability to downregulate or stimulate host immune defense, and raise the pathogenic potential [30, 40, 45-47]. However, recent studies showed that microbiota-derived OMVs carry various compounds, which can influence diverse signaling pathways in the host cells $[48,49]$. This can explain the role of human microbiota in the development of many diseases such as inflammatory bowel disease, metabolic disorders including diabetes, obesity, liver disease as well as autoimmune and cardiovascular or allergic diseases.

Proteomic analysis of Gram-negative bacteria showed that bacterial structures present in OMVs play a role in intercellular bacteria-bacteria and bacteria-host interactions, whereas secreted OMVs are capable of interacting with and adhering to host cells [50]. They constitute the antigen delivery system alternative to well known bacterial secretion systems $[27,45]$. OMVs, which resemble the bacterial surface compounds, can serve as decoys for antibodies and defensins produced in the host, which can unable the bacterial persistence [51, 52]. They are involved in bacterial survival, DNA transfer, acquisition of antibiotic resistance and induction of immune and non-immune cell apoptosis [47, 53-56]. Clinical studies showed anti- and pro-inflammatory properties of OMVs. The polysaccharidic components of Bacteroides fragilis OMVs exhibited anti-inflammatory properties in patients with colitis due to upregulation of regulatory $\mathrm{T}$ cells. On the contrary, pro-inflammatory potential of Moraxella catarrhalis OMVs was shown in patients with chronic obstructive pulmonary disease as well as meningococcal OMVs in sepsis [57-59]. Since bacterial outer membrane compounds display adjuvant-like effects the attempts were made to use OMVs in vaccination protocols $[45,60-63]$.

\section{H. pylori outer membrane vesicles Major components of $H$. pylori OMVs}

$H$. pylori OMVs crossing the cellular barrier are considered as the effective way of $H$. pylori antigens translocation through the gastric mucosa to immune cells in tissues or even to circulation. This mechanism of antigen transport seem to be an alternative for the TSS4 secretion system or to direct secretion of soluble compounds to the surrounding environment $[4,23,25,64]$.

Olofsson et al., using H. pylori OMVs separated by density gradient centrifugation and probed for inner membrane (IM) and outer membrane (OM) markers demonstrated that vesicles of these bacteria contain OM, but not IM compounds [27]. Blebbing of $H$. pylori OM was detected by electron microscopy both in gastric biopsies of infected individuals and in cultures of these bacteria especially during the late stationary growth phase, and during biofilm formation [40, 46, 65].

The content of OMVs might vary among particular $H$. pylori strains as they are encoded by various genes. In $H$. pylori OMVs the following phospholipids were found: phosphatidylglycerol (PG), phosphatidylethanolamine (PE), lyso PE (LPE), phosphatidylcholine (PC), lyso PC (LPC) and cardiolipin [27]. Lipopolysaccharide (LPS) anchored in the outer membrane by lipid A is another important component of $H$. pylori OMVs. The presence of Lewis ${ }^{\mathrm{XY}}$ antigens in an $\mathrm{O}$-specific region of $H$. pylori LPS depends on iron-reach conditions, whereas the presence of Lewis ${ }^{\mathrm{Y}}$ determinants on iron-limited conditions [66-69].

Proteins of $H$. pylori OMVs are divided into five families, containing Hop, Hor, Hof, Hom proteins as well as iron-regulated OMPs and efflux pump OMPs [70]. The following proteins have been identified: vacuolating 
cytotoxin (VacA), CagA, blood group antigen binding adhesin (BabA), sialic acid binding adhesin (SabA), outer inflammatory protein A (OipA), H. pylori neutrophil activating protein (HP-NAP), adherence associated lipoprotein (AlpA), and urease [27, 71]. Most of H. pylori OMVs proteins play a role in adherence, corresponding with the elevated gastric epithelial cell damage and possibly with the gastric cancer development [72-81]. The prevalence of these virulence factors differs among $H$. pylori isolates from various geographic areas, which may be reflected in the incidence of gastric cancer. There is a large intercountry variation in incidence of gastric cancer and $H$. pylori seroprevalence among Asian countries. In Japan, and Taiwan, the infection rate is $39.3 \%$. By contrast, the prevalence of $H$. pylori infection is high in Vietnam (74.6\%) and Bangladesh (92\%), but in these regions low gastric cancer rates have been reported. This has been termed the 'Asian enigma'. Interestingly the majority of $H$. pylori strains isolated from Asian population are $b a b A 2$ gene positive [82-84].

Fujimoto and colleagues showed that $H$. pylori infection with BabA-L strains was associated with highest risk of gastric cancer, followed by BabA-H and BabA-negative strains. In Western countries, infection with BabA-L and BabA-H strains are associated with 54.8-fold and 19.8-fold risk of gastric cancer compared to BabA-negative infectors. Moreover, infection with $H$. pylori BabA-L-positive strain is related with higher colonization rate, neutrophil infiltration, and mucosal atrophy. The involvement of these OipA proteins is not so clear since all $H$. pylori isolates from East Asia are either BabA-H or BabA-L [85]. Furthermore, it was showed that although babA2-genonegative strain was associated with lowest gastric cancer risk in babA2-genopositive strain, a lower BabA expression level seemed to be associated with higher gastric cancer risk [85, 86]. In East Asia a high risk $H$. pylori markers for gastric cancer development include CagL Y58E59 vs non-Y58E59, vacA $s 1$, vacA $i 1, m 1$ and EPIYA-D motif of CagA [87-89].

Apart from these virulence factors (released to the gastric milieu or transported via OMVs) several host-dependent determinants were shown to be involved in higher incidence of gastric cancer. There is a strong association between genetic polymorphisms in the interleukin (IL-) $1 \beta$ and IL-1 receptor gene cluster and in tumor necrosis factor (TNF) $-\alpha$ and the risk of gastric cancer [90, 91]. Interestingly a meta-analysis of the role of IL- $1 \beta$ and it's antagonist gene polymorphisms in gastric cancer risk showed an association in Caucasians, but not in Asian populations [92]. In the context of gastric carcinogenesis, apart from OMVs, bacterial virulence factors that have been implicated include CagA and VacA. Meta-analysis of the relationship between CagA seropositivity and gastric cancer performed by Huang and colleagues showed that infection with CagA-positive strains of $H$. pylori increases the risk for gastric cancer [93]. Similarly, Plummer and co-workers in large epidemiologic study showed a strong relationship between the presence of $H$. pylori DNA in gastric biopsies and the severity of precancerous lesions that is specific to CagA-positive strains [94]. Considering the role of virulence factors involved in the development of gastric cancer development: transported via T4SS system, released upon lysis in the gastric milieu or transported by OMV, apart from their expression, the geographical variability, diet and host-dependent factors should be included [95].

Besides CagA, VacA and OipA proteins, H. pylori OMVs contain different enzymes such as high temperature requirement (HtrA) serine protease, which induces E-cadherin cleavage resulting in the invasion of the gastric epithelium by $H$. pylori, and gamma-glutamyl transpeptidase (GGT), which participates in increasing gastric $\mathrm{pH}$ and glutamine synthesis [96, 97]. The production of some virulence factors associated with OMVs is upregulated in gastric mucosa due to exposure of $H$. pylori to a high concentration of reactive oxygen intermediates [18].

\section{Interaction of $H$. pylori OMVs with gastric epithelial cells}

H. pylori OMVs were found under electron microscope in contact with the plasma membrane of human gastric mucosa cells as well as inside their endosomes, after the incubation with $H$. pylori broth culture filtrates $[98,99]$. The uptake of $H$. pylori OMVs by gastric epithelial cells can occur via clatrin-dependent endocytosis or clatrin independent (lipid raft mediated mechanism), and strongly depends on adhesins exposed on OMVs. It was shown that the presence of VacA toxin may facilitate the OMVs uptake by host cells $[99,100]$. Once OMVs bind to gastric epithelial cells, their components undergo endocytosis and are transported in endosomes, which undergo fusion with lysosomes, further impairing cell functions [99]. Ricci and co-workers showed that approximately $75 \%$ of VacA was released by $H$. pylori in a free-soluble form, while the remaining $25 \%$ was OMV-associated and that vacuolization in cell cultures was due to free-soluble VacA activity of a $H$. pylori broth culture filtrate [101]. This observation suggests that although OMV-associated VacA caused a statistically significant vacuolation, VacA encapsuled in OMVs could play a role different from that of free-soluble toxin such as an alternative delivery system to niches other than gastric mucosa (intestines), where the OMVs containing vesicles might interact with epithelial cells influencing their integrity. However, these aspects of alternative pathological role of OMVs caring VacA need to be further investigated in complex in vitro studies.

In response to vesicle-associated virulence factors, gastric and immune inflammatory cascade is induced (Fig. 1). Components of $H$. pylori OMVs can stimulate the production of both pro- and anti-inflammatory cytokines such as IL-6 and IL-10, respectively, and activate an oxidative burst [102, 103]. Nicotinamide adenine 


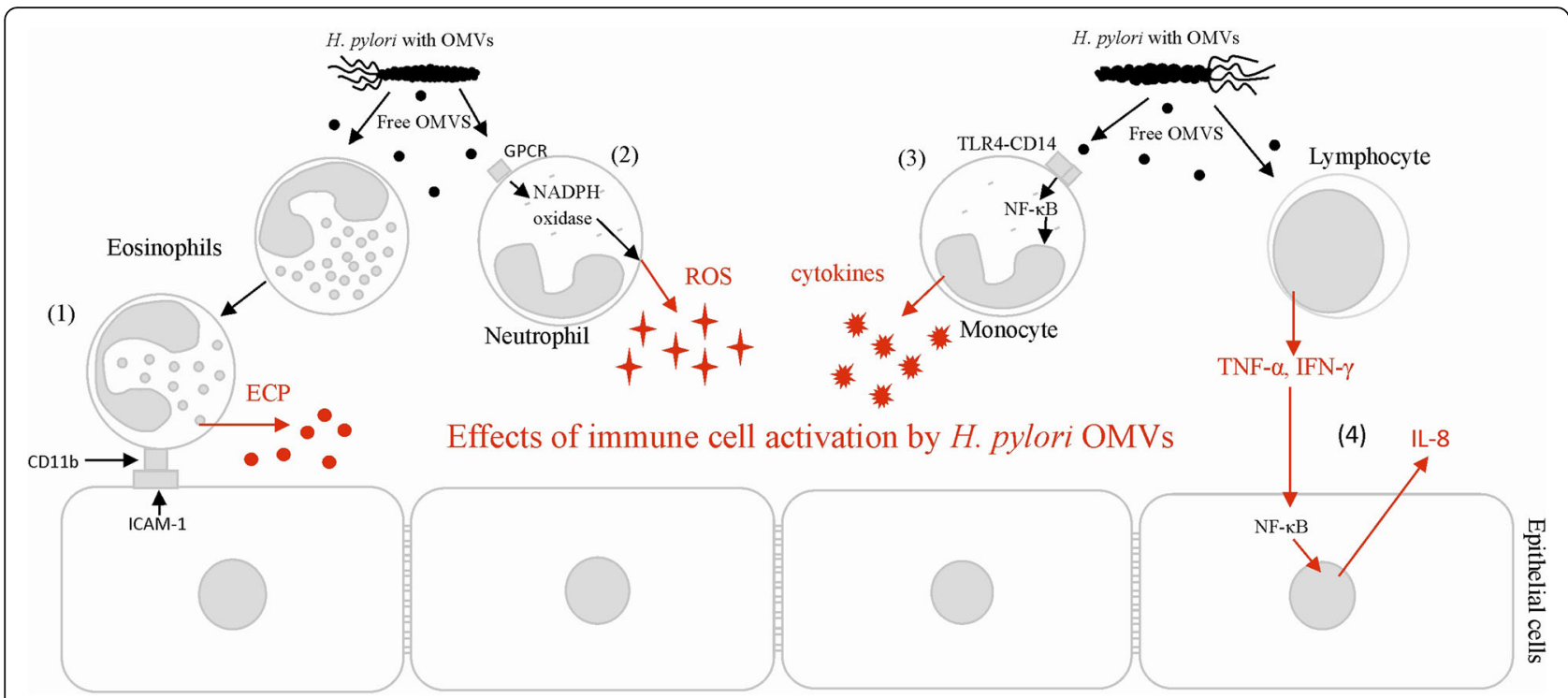

Fig. 1 Various mechanisms of H. pylori outer membrane vesicles (OMVs)-mediated immune responses: (1) H. pylori OMVs induce ICAM-1 (intracellular adhesion molecule)-1 and CD11b (integrin) expression, causing degranulation and ECP (eosinophil cationic protein) release; (2) neutrophil activation via G-protein pathway involving GPCR (G-protein-coupled receptor) and kinases, resulting in oxidative burst and reactive oxygen species (ROS) production due to NADPH oxidase activation; (3) nuclear factor (NF)-kB activation and cytokine release by monocytes involve Toll-like receptor (TLR)4 and CD14 binding with H. pylori ligands delivered by OMV'S; (4) the increase in T-cell activation and cytokine secretion including TNF (tumor necrosis factor)- $a$ and interferon (IFN)- $y$ during H. pylori infection stimulate the release of proinflammatory cytokines such as interleukin (IL)-8 from gastric epithelium through NFkB activation pathway

dinucleotide phosphate (NADPH) oxidase, which mediates this process, has been found to be activated in response to H. pylori OMVs components such as HP-NAP, which upregulates $\beta 2$ integrin expression and attracts leukocytes to epithelial cells $[104,105]$. H. pylori OMVs were also shown to induce human eosinophil degranulation and the release of eosinophil cationic protein (ECP), which enhance the expression of the intracellular adhesion molecule (ICAM)-1 on epithelial cells as well as CD11b integrin on eosinophils $[102,106]$. H. pylori virulence factors delivered by OMVs can target transcription regulators such as a nuclear factor kappa-light-chain-enhancer of activated $\mathrm{B}$ cells (NF-kB), mitogen-activated protein kinase (MAPK) and extracellular signal-regulated kinase (ERK) of the host. On this way OMVs modulate the expression of genes, which products are involved in the inflammatory response, such as the secretion of IL- 8 , TNF- $\alpha$ or IL- $1 \beta$ or proliferation and carcinogenesis $[107,108]$. It was shown that IL-8 production by gastric epithelial cells was stimulated by $H$. pylori OMVs independently of VacA, what suggests that vesicles without this exotoxin can cause cell damage due to induction of inflammatory response [109].

These examples show that $H$. pylori OMVs may strengthen the immune response which lead to diseases development or, on the contrary, promote downregulation of immune reactivity which support infection persistence. Still, the effects of $H$. pylori OMVs on the immune cells are poorly understood. Recently, the influence of $H$. pylori
OMVs with dendritic cells (DC) was described. These interaction resulted in NF- $\mathrm{kB}$ dependent upregulation of heme oxigenase-1 (Ho-1), expression and potentially modulation of DCs function [110].

\section{H. pylori OMVs and disease development}

H. pylori are non-invasive or low invasive and due to this secreted products of these bacteria or those introduced directly into the host cells play a role in the $H$. pylori induced diseases. $H$. pylori - related malignancy is strongly associated with the downregulation of host immunity and induction of structural and functional cell alterations that occur through $H$. pylori virulence factors $[6,111]$. Numerous immune reactions do not require direct host-pathogen contact, thus OMVs of $H$. pylori may amplify its virulence. OMVs of $H$. pylori carrying the CagA affect cell-junctions and associated regulatory proteins, leading to chromatin changes, inappropriate transcription, and promotion of cancer development [112]. H. pylori OMVs containing CagA increases the affinity of ATP to H1 histone, which alters the binding of DNA and histones within the nucleosome [113]. Using transgenic mice expressing the cagA gene, treated with a colitis inducer-dextran sulfate sodium (DSS), it was shown that OMVs carrying CagA and VacA can promote inflammation [107]. Macrophages producing IL-1 $\beta$ and IL-8, as well as gastric epithelial cells secreting IL-8 were involved in that process. These proteins can also induce the expression of interferon (IFN) $-\gamma$ and IL-17 
[114, 115]. Moreover, by exosomes, which are eukaryotic cell-derived vesicles present in body fluids, CagA potentially may promote the development of extragastric diseases, including cardiovascular and haematologic diseases, parkinsonism and other disorders. It was shown that the addition of purified exosomes containing CagA to gastric epithelial cells induced cell elongation, implying that exosomes are functional CagA carriers [116]. Due to this proinflammatory potential of $H$. pylori OMVs, which were detected in gastric juice of patients with gastric cancer is suspected to participate in the process of carcinogenesis $[114,115]$. Recently, Choi and co-workers evaluated the clinical significance of $H$. pylori OMVs on the pathogenesis of gastric malignancy. H. pylori OMVs from gastric juice samples obtained from healthy controls $(\mathrm{HC})$ and patients with duodenal ulcer (DU), gastric ulcer (GU) or gastric cancer (GC) patients were analysed in the context of gastric cancer incidence. The analysis showed that both $H$. pylori cells and $H$. pylori-derived OMVs were present at a significantly higher level in the gastric juices of gastric cancer patients than in normal controls and that the H. pylori-derived OMVs induce inflammation in mice model, which is associated with gastric cancer development [114]. Transmission electron microscopy images showed that the OMVs were spherical in shape regardless of the disease type, however the authors did not present the differences in H. pylori OMV isolated from patients with different gastric outcomes. These results showed the association between OMVs presence and gastric lesions which should be further explored in more appropriate animal model (guinea pig, macaque). Chitcholtan and colleagues observed increased micronuclei formation, alteration in iron metabolism and gluthatione loss in AGS human gastric epithelial cells treated with $H$. pylori OMV, however this effect was observed only in OMV isolated from a toxigenic $H$. pylori strain [115].

H. pylori OMVs are rich in membrane proteins, porins, adhesins and several molecules known to modulate chemokine secretion, cell proliferation and other host cellular processes and constitute a vehicles for the CagA and VacA [117]. Furthermore, a recent analysis of the OMV proteome of 15 clinical isolates of $H$. pylori demonstrated that not all strains express the same proteins or at least not all the proteins were detected in the analysis of the different strains. Several membrane proteins, including Omp11 and BabA, were found to be expressed by all strains. Omp26 was expressed by all disease-related strains but was only present in one out of five strains from asymptomatic carriers, which makes Omp26 a potential target for further investigation in the search for proteins unique to disease-related $H$. pylori strains. The authors suggest that the presence of Omp30 and absence of Omp6 within $H$. pylori OMVs seemed to be associated with $H$. pylori strains causing duodenal ulcer [118]. It was also recently shown that the size of $H$. pylori OMVs determines its content. The proteomic analysis revealed that larger OMVs contain significantly more adhesins (Hop, SabA, BabA) compared to smaller OMVs, and that most of the H. pylori proteins related with metabolism are associated within smaller OMVs. Interestingly, proteins associated with $H$. pylori survival or virulence were common to both small and large OMVs, including: urease A and B subunits, neutrophil activating protein, VacA, and the porin HopA [119].

As mentioned above, VacA, present in OMVs may bind to the lipid bilayer in the cell membrane of the host cells and form anion-selective and voltage-dependent channels that increase the efflux of complex molecules - this, in consequence may facilitate the growth of $H$. pylori $[81,120]$. Soluble and OMVs bound VacA induces apoptosis in gastric epithelial cells via the mitochondria-dependent pathway, which is initiated by the cytochrome $\mathrm{c}$ release. This mechanism occurs indirectly due to VacA-mediated activation of proapoptopic $\mathrm{Bcl}-2$ proteins: $\mathrm{Bcl}-2$-associated $\mathrm{X}$ protein (Bax) and Bcl-2 homologous antagonist killer (Bak), which increase the permeability of the mitochondrial membrane [121]. Binding of the p55-58 VacA domain to host receptors, such as low density lipoprotein receptor-related protein 1 (LRP1) may also result in generation of reactive oxygen species (ROS) and the induction of cell autophagy followed by formation of autophagosome and then apoptosis [122]. Furthermore, the p33-37 VacA domain also induces apoptosis by the accumulation of connexin 43 (Cx43) in autophagic vesicles via the Ras-related C3 botulinum toxin substrate 1 (Rac1)/ERK dependent pathway, and similarly to CagA, VacA may induce NF- $\mathrm{kB}$-dependent apoptosis $[123,124]$. The induction of cell apoptosis in response to soluble or OMVs bound VacA is showed in Fig. 2. It has been found that supernatants from the broth cultures of $H$. pylori, mostly of toxigenic strains, induce apoptosis by the receptor-ligand pathway, which involves the CD95 ligand (CD95L) and the CD95 receptor (Fas) [125]. T-cells and the cytokines they release such as TNF- $\alpha$ and IFN- $\gamma$ occur at higher levels in the gastric epithelium of $H$. pylor$i$-infected patients, and increase local Fas expression [126]. H. pylori may also induce apoptosis via the interaction of soluble or OMVs bound urease to class II major histocompatibility complex (MHC II) molecules, which are expressed in epithelial cells and play a key role in pathogen recognition [127]. The ability of $H$. pylori components associated with OMVs to induce cell apoptosis may potentially contribute to the development of $H$. pylor$i$-related diseases. Enhanced loss of epithelial cells due to H. pylori-induced apoptosis promote the development of gastric atrophy, which predisposes to neoplasia (Fig. 3a). Alternatively, apoptosis may be a response to hyperproliferation accompanied by an increased prevalence of mutations - as a way to reduce excessive growth of abnormal cells. It should be taken into account that apoptosis may also protect against deleterious effects of inflammatory 


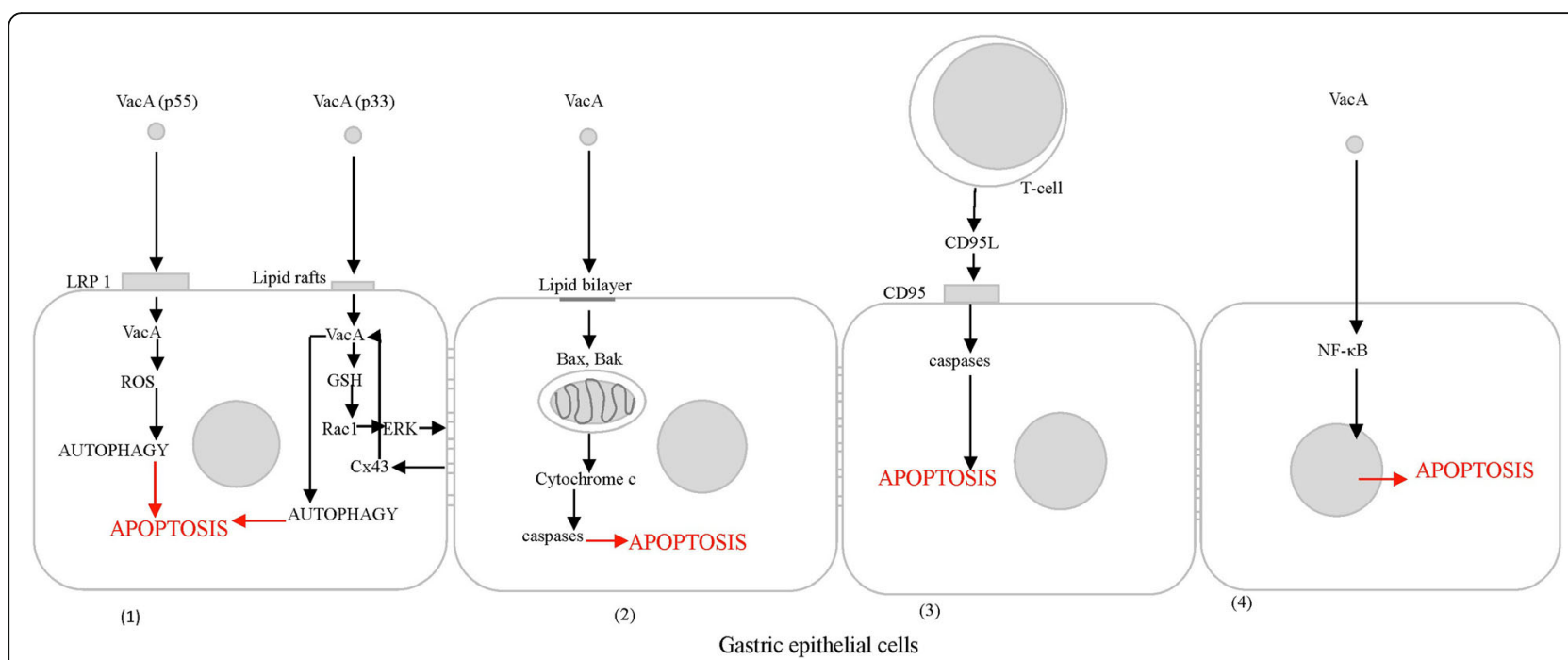

Fig. 2 Distinct mechanisms of cell apoptosis induction by H. pylori VacA: (1) induction of apoptosis via autophagy, (2) cytochrome c release from mitochondria, (3) CD95-CD95L binding or (4) NFKB activation

response [128]. On the other hand, the induction of apoptosis in lymphocytes or antigen presenting cells by $H$. pylori components, free or OMVs bound, may diminish clonal expansion and the effectiveness of specific anti- $H$. pylori immune responses $[129,130]$.

The H. pylori components present in OMVs such as LPS may induce opposite effects. The endotoxic activity of $H$. pylori LPS is lower than the activity of LPS of other Gram-negative bacteria due to distinct structure of lipid A. Thus OMVs decorated with $H$. pylori LPS may downregulate the inflammatory response or lead to it's upregulation by the induction of fibrinolytic components $[131,132]$. $H$. pylori LPS due to presence of Lewis antigens in O-specific polysaccharide chains, which share a common structure with blood group-related components of the host may lead to generation of autoimmunity due to the stimulation of autoantibody production [103]. Lewis antigens present in LPS bound to OMVs can contribute to chronic stimulation of the host immune cells. The ability of OMVs to bind and diminish the level of anti-Lewis antibodies from the sera of H. pylori infected individuals indicate that OMVs may potentially play a role in autoimmune processes related to $H$. pylori infection [69]. The above examples show that $H$. pylori OMVs may strengthen the immune response leading

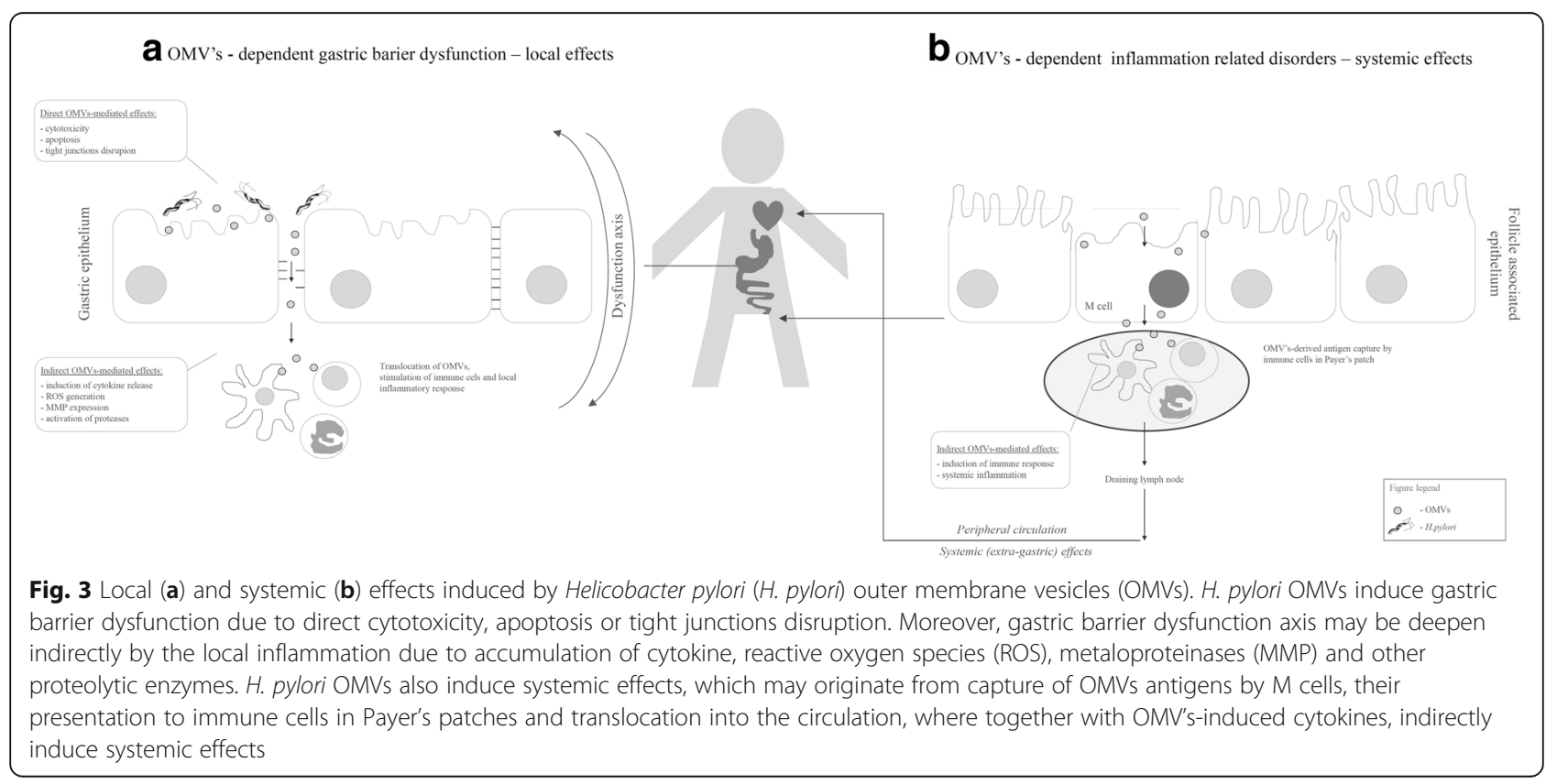


to diseases development or promote reduction of immune reactivity and thus support the infection persistence.

H. pylori OMVs due to the induction of gastric barrier instability and dysbiosis can be translocated to deeper layers of gastric mucosa and gastrointestinal tract. OMVs have a proper size $(20-200 \mathrm{~nm})$ to enable their entry by circulation into lymph vessels and uptake by antigen presenting cells. Smaller OMVs ranging from 20 to $100 \mathrm{~nm}$ in size preferentially entered host cells via caveolin-mediated endocytosis. Whereas larger OMVs ranging between 90 and $450 \mathrm{~nm}$ in size entered host epithelial cells via macropinocytosis and endocytosis [133]. Several biological functions have been suggested for natural OMVs. Naturally occurring OMVs may function as long distance delivery system of specific components (Fig. 3b) [134]. This natural feature of bacterial OMVs is already used in medicine to deliver vaccine components to different sites in the organism, including circulation e.g. OMVs are used in the first generation vaccine product that has been approved for the market as well as for drug-delivery development including anti-H.pylori therapy studied on animal model [135]. Considering that, one can hypothesize that OMVs present in the circulation, by the interaction with epithelial cells and leukocytes, might affect the responsiveness of other immune cells of the host [136]. One class of vesicles termed exosomes is produced by exocythosis of multivesicular bodies. It was showed that CagA is present in exosomes derived from serum of patients infected with cagA-positive strains [137]. These may suggest that secreted exosomes may enter a bloodstream, and be delivered to different organs. Other group reported that $H$. pylori OMV localizes in a close vicinity of the tight junction protein $\mathrm{ZO}-1$ and induce changes connected with cell barrier instability [138]. This way of translocation of $H$. pylori virulence factors can elucidate the involvement of $H$. pylori compounds in the development of local as well as systemic inflammation - crucial for the initiation or the maintenance of gastric and extragastric inflammatory diseases $[6,15,139,140]$.

\section{Conclusions and future research}

In conclusion, outer membrane vesicles are continuously shed by $H$. pylori from the surface of these bacteria during infection. The composition of H. pylori OMVs and their ability to translocate via gastric barrier to intestines and into circulation suggests that they may play a central role in H. pylori pathogenesis by acting as delivery vehicles to transport virulence factors. Locally, OMVs induce direct effects such as tight junction disruption, cytotoxicity or apoptosis or indirectly affect the immune cells to release cytokines, proteases or tissue damaging factors such as MMP or ROS. Their translocation from gastric niche through digestive system into intestines may possibly lead to a capture and presentation by $\mathrm{M}$ cells to other immune cells and result with the immunomodulation of immune mechanisms leading to spread of OMVs into circulation. The studies concerning the involvement of OMVs produced by $H$. pylori in the pathogenesis of extra-gastric diseases such as coronary heart disease or food allergies might explain their importance and mechanisms by which they promote inflammation or tolerance.

\section{Abbreviations}

ABC: ATP-binding cassette; Alp: Adherence associated lipoproteins; BabA: Blood group antigen-binding adhesin A; CagA: Cytotoxin-associated gene A; CD95L: CD95 ligand; Cx43: Connexin 43; DC: Dendritic cell; DSS: Dextran sulfate sodium; ECP: Eosinophil cationic protein; eDNA: Extracellular DNA; ERK: Extracellular signal-regulated kinase; ETEC: Enterotoxigenic E. coli; GGT: Gamma-glutamyl transpeptidase; GPCR: Gprotein-coupled receptor; Ho-1: oxygenase-1; HP-NAP: H. pylori neutrophil activating protein; $\mathrm{HtrA}$ : High temperature requirement A; ICAM-

1: Intracellular adhesion molecule-1; IFN: Interferon; IL: Interleukin; IM: Inner membrane; Le: Lewis antigenic determinant; LPC: Lysophosphatidylcholine; LPE: Lysophosphatidyl ethanolamine; LPS: Lipopolysaccharide;

LRP1: Lipoprotein receptor-related protein 1; MAPK: Mitogen-activated protein kinase; MHC: Major histocompatibility complex;

MMP: Metalloproteinase; NADPH: Nicotinamide adenine dinucleotide phosphate; NFkB: Nuclear factor kappa-light-chain-enhancer of activated B cells; OipA: Outer inflammatory protein A; OM: Outer membrane; OMPs: Outer membrane proteins; OMVs: Outer membrane vesicles; PC: Phosphatidylcholine; PE: Phosphatidylethanolamine; PG: Phosphatidylglycerol; pOMVS: Planktonic OMVs; Rac1: Ras-related C3 botulinum toxin substrate 1; ROS: Reactive oxygen species; SabA: Sialic acidbinding adhesin; T4SS: Type IV secretion system; TLR: Toll-like receptor; TNF: Tumor necrosis factor; VacA: Vacuolating cytotoxin A

\section{Acknowledgements \\ Not applicable.}

\section{Funding}

Not applicable.

\section{Availability of data and materials} Not applicable.

\section{Authors' contributions}

MC designed and wrote the manuscript, NC collected literature, prepared figures and tables, KR wrote, edited and prepared the manuscript for submission, prepared answers to reviewer's suggestions. All authors read and approved the final manuscript.

Ethics approval and consent to participate

Not applicable.

Consent for publication

Not applicable.

\section{Competing interests}

The authors declare that they have no competing interests.

\section{Publisher's Note}

Springer Nature remains neutral with regard to jurisdictional claims in published maps and institutional affiliations.

Received: 4 June 2018 Accepted: 24 October 2018 Published online: 08 November 2018

\section{References}

1. Lee A. Spiral organisms: what are they? A microbiologic introduction of Helicobacter pylori. Scand J Gastroenterol Suppl. 1991;187:9-22.

2. Kelly DJ. The physiology and metabolism of the human gastric pathogen Helicobacter pylori. Adv Microb Physiol. 1998;40:137-89. 
3. Semino-Mora C, Doi SQ, Marty A, Simko V, Carlstedt I, Dubois A. Inrtacellular and intestinal expression of Helicobacter pylori virulence genes in gastric precancerous intestinal metaplasia and adenocarcinoma. J Infect Dis. 2003; 187:1165-77. https://doi.org/10.1086/368133.

4. Backert S, Clyne M, Tegtmeyer N. Molecular mechanisms of gastric epithelial cell adhesion and injection of CagA by Helicobacter pylori. Cell Commun Signal. 2011;9:28. https://doi.org/10.1186/1478-811X-9-28.

5. Wang YH, Wu JJ, Lei HY. When Helicobacter pylori invades and replicates in the cells. Autophagy. 2009;5:540-2. https://doi.org/10.4161/auto.5.4.8167.

6. Kusters JG, Van Vliet AH, Kuipers EJ. Pathogenesis of Helicobacter pylori infection. Clin Microbiol Rev. 2006;19:449-90. https://doi.org/10.1128/CMR.00054-05.

7. Brown LM. Helicobacter pylori: Epidemiology and routes of transmission. Epidemiol Rev. 2000;22:283-97.

8. Malaty HM. Epidemiology of Helicobacter pylori infection. Best Pract Res Clin Gastroenterol 2007;21:205-214; doi:10.1016/j.bpg.2006.10.005

9. Chang YW, Han YS, Lee DK, Kim HJ, et al. Role of Helicobacter pylori infection among offspring or siblings of gastric cancer patients. Int J Cancer. 2002;101:469-74. https://doi.org/10.1002/ijc.10637.

10. Dubois A, Berg DE, Incecik ET, et al. Transient and persistent experimental infection of nonhuman primates with Helicobacter pylori: Implications for human disease. Infect Immun. 1996;64:2885-91.

11. Mladenova-Hristova I, Grekova O, Patel A. Zoonotic potential of Helicobacter spp. J Microbiol Immunol Infect 2017; pii: S1684-1182(17) 30055-5 doi: https://doi.org/10.1016/j.jmii.2016.11.003

12. Bode G, Mauch F, Malfertheiner P. The coccoid forms of Helicobacter pylori. Criteria for their viability. Epidemiol Infect. 1993;111:483-90.

13. Brown LM, Osato M, You WC, et al. Disinfection of endoscopes from Helicobacter pylori-positive subjects: Evaluation of the effectiveness of the Chinese Calijing disinfection kit. Am J Infect Control 2005;33:197-201; doi:10. 1016 /j.ajic.2004.11.002.

14. Thorell K, Yahara K, Berthenet E, et al. Rapid evolution of distinct Helicobacter pylori subpopulations in the Americans. PLoS Genet. 2017;13: e1006546. https://doi.org/10.1371/journal.pgen.1006546.

15. Clyne M, Dolan B, Reeves EP. Bacterial factors that mediate colonization of the stomach and virulence of Helicobacter pylori. FEMS Microbiol Lett. 2007; 268:135-43. https://doi.org/10.1111/j.1574-6968.2007.00648.x.

16. Moran AP, Knirel YA, Senchenkova SN, Widmalm G, Hynes SO, Jansson P. Phenotypic variation in molecular mimicry between Helicobacter pylori lipopolysaccharides and human gastric epithelial cell surface glycoforms. Acid-induced phase variation in Lewis ${ }^{x}$ and Lewis ${ }^{y}$ expression by H. pylori lipopolysaccharides. J Biol Chem. 2002;277:5785-95. https://doi.org/10.1074/ jbc.M108574200.

17. Ernst FD, Homuth G, Stoof J, et al. Iron-responsive regulation of the Helicobacter pylori iron-cofactored superoxide dismutase SodB is mediated by fur. J Bacteriol. 2005;187:3687-92. https://doi.org/10.1128/JB.187.11.3687-3692.2005.

18. Huang $\mathrm{CH}$, Chiou SH. Proteomic analysis of upregulated proteins in Helicobacter pylori under oxidative stress induced by hydrogen peroxide. Kaoshiung J Med Sci. 2011;27:544-53. https://doi.org/10.1016/j.kjms.2011.06.019.

19. Chmiela M, Czkwianianc E, Wadstrom T, Rudnicka W. Role of Helicobacter pylori surface structures in bacterial interaction with macrophages. Gut. 1997:40:20-4.

20. Paziak-Domańska B, Chmiela M, Jarosińska A, Rudnika W. Potential role of CagA in the inhibition of T cell reactivity in Helicobacter pylori infection. Cell Immunol. 2000;202:136-9. https://doi.org/10.1006/cimm.2000.1654

21. Raghavan S, Quiding-Jarbrink M. Immune modulation by regulatory T cells in Helicobacter pylori-associated diseases. Endocr Metab Immune Disord Drug Targets. 2012;12:71-85. https://doi.org/10.2174/ 187153012799278974.

22. Rudnicka K, Miszczyk E, Matusiak A, et al. H. pylori driven modulation of NK cell expansion, intracellular cytokine expression and cytotoxic activity. Innate Immun. 2015;21:127-39. https://doi.org/10.1177/1753425913518225.

23. Wang YH, Gorvel JP, Chu YT, Wu JJ, Lei HY. Helicobacter pylori impairs murine dendritic cell responses to infection. PLOSone 2010;5:e10844; doi:10. 1371/journal.pone.0010844]10.1371/journal.pone.0010844].

24. Covacci A, Censini B, Bugnoli M, et al. Molecular characterization of the 128-kDa immunodominant antigen Helicobacter pylori associated with cytotoxicity and duodenal ulcer. Proc Natl Acad Sci U S A. 1993;90:5791-5.

25. Terradot L, Waksman G. Architecture of H. pylori Cag-type IV secretion system. FEBS J. 2011;278:1213-22. https://doi.org/10.1111/j. 1742-4658.2011.08037.x.

26. Wessler S, Backert S. Molecular mechanisms of epithelial -barrier disruption by Helicobacter pylori. Trends Microbiol. 2008;16:397-405. https://doi.org/10. 1016/j.tim.2008.05.005.
27. Olofsson A, Vallström A, Petzold $K$, et al. Biochemical and functional characterization of Helicobacter pylori vesicles. Mol Microbiol. 2010;77:153955. https://doi.org/10.1111/j.1365-2958.2010.07307.x.

28. Cullen TW, Giles DK, Wolf LN, Ecobichon C, Boneca IG, Trent MS. Helicobacter pylori versus the host: remodeling of the bacterial outer membrane is required for survival in the gastric mucosa. PLoS Pathog. 2011; 7:e1002454. https://doi.org/10.1371/journal.ppat.1002454.

29. Van der Pol E, Boing AN, Harrison P, Sturk A, Nieuwland R. Classification, functions, and clinical relevance of extracellular vesicles. Pharmacol Rev 2012;64:676-705; doi:10.1124 /pr.112.005983.

30. Kuehn MJ, Kesty NC. Bacterial outer membrane vesicles and the host-pathogen interaction. Genes Dev. 2005;19:2645-55. https://doi.org/10.1101/gad.1299905.

31. Kim JH, Lee J, Park J, Gho YS. Gram-negative and Gram-positive bacteria extracellular vesicles. Semin Cell Dev Biol. 2015;40:97-104. https://doi.org/10. 1016/j.semcdb.2015.02.006.

32. Deatherage BL, Lara JC, Bergsbaken T, Rassoulian Barrets SL, Lara S, Cookson BT. Biogenesis of bacterial outer mambrane vesicles. Mol Microbiol. 2009;72: 1395-407. https://doi.org/10.1111/j.1365-2958.2009.06731.x.

33. Kondo M, Kawai K, Yagyu K, Nakayama K, Kurohara K, Oshima S. Changes in the cell structure of Flavobacterium psychrophilum with length of culture. Microbiol Immunol. 2001;45:813-8. https://doi.org/10.1111/j.1348-0421.

34. Chatterjee SN, Das J. Electron microscopic observations on the excretion of cell-wall material by Vibrio cholerae. J Gen Microbiol. 1967;49:1-11. https:// doi.org/10.1099/00221287-49-1-1.

35. Ellis TN, Kuehn MJ. Virulence and immunomodulatory roles of bacterial outer membrane vesicles. Microbiol Mol Biol Rev. 2010;74:81-94. https://doi. org/10.1128/MMBR.00031-09.

36. Zhou L, Srisatjaluk R, Justus DE, Doyle RJ. On the origin of membrane vesicles in Gram-negative bacteria. FEMS Microbiol Lett. 1998;163:223-8. https://doi.org/10.1111/j.1574-6968.1998.tb13049.x.

37. Wensink J, Witholt B. Outer-membrane vesicles released by normally growing Escherichia coli contain very little lipoprotein. Eur J Biochem. 1981; 116:331-5. https://doi.org/10.1111/j.1432-1033.1981.tb05338.x

38. Mashbrun LM, Whiteley M. Membrane vesicles traffic signals and facilitate group activities in a prokaryote. Nature. 2005;437:422-5. https://doi.org/10.1038/nature03925.

39. Roier S, Zingl FG, Cakar F, et al. A novel mechanism for the biogenesis of outer membrane vesicles in Gram-negative bacteria. Nat Commun. 2016;7: 10515. https://doi.org/10.15698/mic2016.06.508.

40. Grande R, Di Marcantonio MC, Robuffo I, et al. Helicobacter pylori ATCC 43629/NCTC 11639 outer membrane vesicles (OMVs) from biofilm and planktonic phase associated with extracellular DNA (eDNA). Front Microbiol. 2015;6:1369. https://doi.org/10.3389/fmicb.2015.01369.

41. Turner L, Praszkier J, Hutton ML, et al. Increased outer membrane vesicle formation in a Helicobacter pylori tolB mutant. Helicobacter. 2015;20:269-83. https://doi.org/10.1111/hel.12196.

42. Katsui N, Tsuchido T, Hiramatsu R, Fujikawa S, Takano M, Shibasaki I. Heatinduced blebbing and vesiculation of the outer membrane of Escherichia coli. J Bacteriol. 1982;151:1523-31.

43. McBroom AJ, Kuehn MJ. Release of outer membrane vesicles by gramnegative bacteria is a novel stress response. Mol Microbiol. 2007;63:545-58. https://doi.org/10.1111/j.1365-2958.2006.05522.x.

44. Dutson TR, Pearson AM, Price JF, Spink GC, Tarrant PJV. Observations by electron microscopy on pig muscle inoculated and incubated with Pseudomonas fragi. Appl Microbiol. 1971;22:1152-8.

45. Lee J, Kim OY, Gho YS. Proteomic profiling od Gram-negative bacterial outer membrane vesicles: current perspectives. Proteomics Clin Appl. 2016; 10:897-909. https://doi.org/10.1002/prca.201600032.

46. Yonezawa $\mathrm{H}$, Osaki T, Woo T, et al. Analysis of outer membrane vesicle protein involved in biofilm formation of Helicobacter pylori. Anaerobe. 2011; 17:388-90. https://doi.org/10.1016/j.anaerobe.2011.03.020.

47. Li Z, Clarke AJ, Beveridge TJ. A major autolysin of Pseudomonas aeruginosa: Subcellular distribution, potential role in cell growth and division, and secretion in surface membrane vesicles. J Bacteriol. 1996;178:2479-88.

48. Canas MA, Gimenez R, Fabrega MJ, Toloza L, Baldoma L, Badia J. Outer membrane vesicles from the probiotic Escherichia coli Nissle 1917 and the commensal ECOR12 enter intestinal epithelial cell via clathrin-dependent endocytosis and elicit differential effects on DNA damage. PloSOne. 2016;11:e0160374. https://doi.org/10.1371/journal. pone.0160374 
49. Badi SA, Moshiri A, Fateh A, et al. Microbiota-derived extracellular vesicles as new systemic regulators. Front Microbiol. 2017;8:1-4. https://doi.org/10. 3389/fmicb.2017.016 10.

50. Zeng M, Inohara N, Nuez G. Mechanisms of inflammation-driven bacterial dysbiosis in the gut. Mucosal Immunol. 2017;10:18-26. https://doi.org/10. 1038/mi.2016.75.

51. Manning AJ, Kuehn MJ. Contribution of bacterial outer membrane vesicles to innate bacterial defense. BMC Microbiol. 2011;11:258. https://doi.org/10. 1186/1471-2180-11-258.

52. Schaar V, Paulsson M, Morgelin M, Riesbech K. Outer membrane vesicles shield Moraxella catarrhalis $\beta$-lactamase from neutralization by serum lgG. J Antimicrob Chemother. 2013;68:593-600. https://doi.org/10.1093/jac/dks444.

53. Yaron S, Kolling GL, Simon L, Matthews KR. Vesicle mediated transfer of virulence genes from Escherichia coli 0157:H7 to other enteric bacteria. Appl Environ Microbiol. 2000:66:4414-20.

54. Mack M, Kleischmidt A, Bruhl H, Klier C, et al. Transfer of the chemokine receptor CCR5 between cells by membrane-derived microparticles: a mechanism for cellular human immunodefficiency virus 1 infection. Nat Med. 2000;6:769-75. https://doi.org/10.1038/77498.

55. Lenassi M, Cagney G, Liao $M$, et al. HIV Nef is secreted in exosomes and triggers apoptosis of bystander CD4 ${ }^{+} T$ cells. Traffic. 2000;11:110-22. https:// doi.org/10.1111/j.1600-0854.2009.01006.x.

56. Dorward DW, Garon CF, Judd RC. Export and intercellular transfer of DNA via membrane blebs of Neisseria gonorrhoeae. J Bacteriol. 1989;171:2499-505.

57. Shen Y, Giardino Torchia ML, Lawson GW, et al. Outer membrane vesicles of a human commensal mediate immune regulation and disease protection. Cell Host Microbe. 2012;12:509-20. https://doi.org/10.1016/j. chom.2012.08.04

58. Schaar V, de Vries SP, Perez Vidavics ML, et al. Multicomponent Moraxella catarrhalis outer membrane vesicles induce an inflammatory response and are internalized by human epithelial cells. Cell Microbiol. 2011;13:432-49. https://doi.org/10.1111/j.1462-5822.2010.01546.x.

59. Namork E, Brandtzaeg P. Fatal meningococcal septicaemia with "blebbing" meningococcus Lancet 2002;360:1741; doi:10.1016/SO140-6736(02)11721-1.

60. Jan AT. Outer membrane vesicles (OMVs) of Gram-negative bacteria: a perspective update. Front Microbiol. 2017;8:1053. https://doi.org/10.3389/ fmicb.2017.01053.

61. Lee DH, Kim SH, Kang W, et al. Adjuvant effect of bacterial outer membrane vesicles with penta-acylated lipopolysaccharide on antigen-specific T cell priming. Vaccine. 2011;29:8293-301. https://doi.org/10.1016/j.vaccine. 2011.08.102.

62. Corrado C, Raimondo S, Chiesi A, Cicca F, De Leo G, Alessandro R. Exosomes as uintercellular signaling organelles involved in health and disease: basic science and clinical applications. Int J Mol Sci. 2013;14:5338-66. https://doi. org/10.3390/ijms14035338

63. Moshri A, Dashtbani-Roozbehani A, Najar Peerayeh S, Siadat SD. Outer membrane vesicle: a macromolecule with multifunctional activity. Hum Vaccin Immunotehr. 2012:8:953-5. https://doi.org/10.4161/hv.20166.

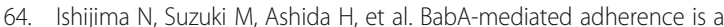
potentiator of the Helicobater pylori type IV secretion system activity. J Biol Chem. 2011:286:25256-64. https://doi.org/10.1074/ jbc. M111. 233601

65. Keenan J, Day T, Neal S, et al. A role for the bacterial outer membrane in the pathogenesis of Helicobacter pylori infection. FEMS Microbiol Lett. 2000;182:259-64.

66. Aspholm M, Olfat FO, Nordén J, et al. SabA is the H. pylori hemagglutinin and is polymorphic in binding to sialylated glycans. PLoS Pathog. 2006;2: e110. https://doi.org/10.1371/ journal.ppat.0020110.

67. Alexander C, Rietschel ET. Bacterial lipopolysaccharides and innate immunity. J Endotoxin Res. 2001;7:167-202.

68. Keenan Jl, Davis KA, Beaugie CR, McGovern JJ, Moran AP. Alterations in Helicobacter pylori outer membrane and outer membrane vesicle-associated lipopolysaccharides under iron-limiting growth conditions. Innate Immun. 2008;14:279-90. https://doi.org/10.1177/175342 5908096857.

69. Hynes SO, Keebnan J, Ferris JA, Annuk H, Moeran AP. Lewis epitopes on outer membrane vesicles of relevance to Helicobacter pylori pathogenesis. Helicobacter. 2005;10:146-56. https://doi.org/10.1111/j.1523-5378.2005.00302.

70. Oleastro M, Ménard A. The role of Helicobacter pylori outer membrane proteins in adherence and pathogenesis. Biology 2013;2:1110-1134; doi: 24833057 DOl:https://doi.org/10.3390/biology2031110

71. Lekmeechai S, Su YC, Brant M, Alvarado-Kristensson M, Vallström A, Obi I, Arnqvist A, Riesbeck K. Helicobacter pylori outer membrane vesicles protect the pathogen from reactive oxygen species of the respiratory burst. Front Microbiol. 2018;9:1837. https://doi.org/10.3389/fmicb.2018.01837.
72. Heczko U, Smith VC, Meloche RM, Buchan AMJ, Finlay BB. Characteristics of Helicobacter pylori attachment to human primary antral epithelial cells. Microbes Infect. 2000;2:1669-76. https://doi.org/10.1016/S12864579(00)01322-8.

73. Loh JT, Torres VJ, Algood HM, McClain MS, Cover TL. Helicobacter pylori HopQ outer membrane protein attenuates bacterial adherence to gastric epithelial cells. FEMS Microbiol Lett. 2008;289:53-8.

74. Belogolova E, Bauer B, Pompaiah M, et al. Helicobacter pylori outer membrane protein HopQ identified as a novel T4SS-associated virulence factor. Cell Microbiol. 2013;15:1896-912. https://doi.org/10.1111/cmi.12158.

75. Exner MM, Doig P, Trust TJ, Hancock REW. Isolation and characterization of a family of porin proteins from Helicobacter pylori. Infect Immun. 1995;63:1567-72.

76. Doig P, Exner MM, Hancock RE, Trust TJ. Isolation and characterization of a conserved porin protein from Helicobacter pylori. J Bacteriol. 1995;177:5447-52.

77. Senkovich OA, Yin J, Ekshyyan V, et al. Helicobacter pylori AlpA and AlpB bind host laminin and influence gastric inflammation in gerbils. Infect Immun. 2011;79:3106-16. https://doi.org/10.1128/IAI.01275-10.

78. Dossumbekova A, Prinz C, Mages J, et al. Helicobacter pylori HopH (OipA) and bacterial pathogenicity: genetic and functional genomic analysis of hopH gene polymorphisms. J Infect Dis. 2006;194:1346-55. https://doi.org/ $10.1086 / 508426$

79. Kennemann L, Brenneke B, Andres S, et al. In vivo sequence variation in HopZ, a phase-variable outer membrane protein of Helicobacter pylori. Infect Immun. 2012;80:4364-73. https://doi.org/10.1128/IAl.00977-12.

80. Telebi BAA, Rafiei A, Ajami A, et al. Helicobacter pylori homB, but not cagA is associated with gastric cancer in Iran. J Clin Microbiol. 2011;49:3191-6. https://doi.org/10.1128/JCM.00947-11.

81. Jones KR, Whitmire JM, Merrell DS. A tale of two toxins: Helicobacter pylori CagA and VacA modulate host pathways that impact disease. Front Microbiol. 2010;1:115. https://doi.org/10.3389/fmicb.2010.00115.

82. Miwa H, Go MF, Sato N. H. pylori and gastric cancer: the Asian enigma. Am Gastroenterol. 2002;97(5):1106-12.

83. Fock KM, Ang TL. Epidemiology of Helicobacter pylori infection and gastric cancer in Asia. J Gastroenterol Hepatol. 2010;3:479-86.

84. Yamaoka Y, Kato M, Asaka M. Geographic differences in gastric cancer incidence can be explained by differences between Helicobacter pylori strains. Inter Med. 2008;47:1077-83.

85. Fujimoto S, Olaniyi Ojo O, Arnqvist A, Wu JY, Odenbreit S, Haas R, et al. Helicobacter pylori BabA expression, gastric mucosal injury, and clinical outcome. Clin Gastroenterol Hepatol. 2007;5(1):49-58.

86. Sheu SM, Sheu BS, Chiang WC, Kao CY, Wu HM, Yang HB, et al. H pylori clinical isolates have diverse $b a b A B$ genotype distributions over different topographic sites of stomach with correlation to clinical disease outcomes. BMC Microbiol. 2012;12:89.

87. Sugimoto M, Zali MR, Yamaoka Y. The association of vacA genotypes and Helicobacter pylori-related gastroduodenal diseases in the Middle East. Eur J Clin Microbiol Infect Dis. 2009:28(10):1227-36.

88. Li Q, Liu J, Gong Y, Yuan Y. Association of CagA EPIYA-D or EPIYA-C phosphorylation sites with peptic ulcer and gastric cancer risks: a metaanalysis. Medicine (Baltimore). 2017;96(17):e6620

89. Yeh YC, Chang WL, Yang HB, Cheng HC, Wu JJ, Sheu BS. H. pylori cagL amino acid sequence polymorphism Y58E59 induces a corpus shift of gastric integrin alpha5beta1 related with gastric carcinogenesis. Mol Carcinog. 2011;50(10):751-9.

90. Furuta T, Shirai N, Sugimoto M. Controversy in polymorphisms of interleukin-1 beta in gastric cancer risks. J Gastroenterol. 2004;39:501-3.

91. El-Omar EM, Carrington M, Chow WH, et al. Interleukin-1 polymorphisms associated with increased risk of gastric cancer. Nature. 2000;404:398-402.

92. Camargo MC, Mera R, Correa P, et al. Interleukin-1 beta and interleukin-1 receptor antagonist gene polymorphisms and gastric cancer: a metaanalysis. Cancer Epidemiol Biomark Prev. 2006;15:1674-87.

93. Huang JQ, et al. Meta-analysis of the relationship between cagA seropositivity and gastric cancer. Gastroenterology. 2003;125:1636-44.

94. Plummer $\mathrm{M}$, et al. Helicobacter pylori cytotoxin-associated genotype and gastric precancerous lesions. J Natl Cancer Inst. 2007;99:1328-34.

95. Chang $W L$, Yeh YC, Sheu BS. The impacts of $H$. pylori virulence factors on the development of gastroduodenal diseases. J Biomed Sci. 2018;25(1):68.

96. Löwer M, Geppert T, Schneider P, Hoy B, Wessler S, Schneider G. Inhibitors of Helicobacter pylori protease HtrA found by 'virtual ligand' screening combat bacterial invasion of epithelia. PLoS One. 2011;6:e17986. https://doi. org/10.1371/journal.pone.0017986. 
97. Ricci V, Giannouli M, Romano M, Zarrilli R. Helicobacter pylori gammaglutamyl transpeptidase and its pathogenic role. World J Gastroenterol. 2014;20:630-8. https://doi.org/10.3748/wjg.v20.i3.630.

98. Fiocca R, Necchi V, Sommi P, et al. Release of Helicobacter pylori vacuolating cytotoxin by both a specific secretion pathway and budding of outer membrane vesicles. Uptake of released toxin and vesicles by gastric epithelium. J Pathol. 1999;188:220-6. https://doi.org/10.1002/(SICI)10969896(199906)188:2<220::AID-PATH307>3.0.CO:2-C.

99. Parker H, Chitcholtan K, Hampton MB, Keenan Jl. Uptake of Helicobacter pylori outer membrane vesicles by gastric epithelial cells. Infect Immun. 2010;78:5054-61. https://doi.org/10.1128//Al.00299-10.

100. Kaparakis M, Turnbull L, Carneiro L, et al. Bacterial membrane vesicles deliver peptidoglycan to NOD1 in epithelial cells. Cell Microbiol. 2010;12:372-85. https://doi.org/10.1111/j.1462-5822.2009.01404.x.

101. Ricci V, Chiozzi V, Necchi V, Oldani A, Romano M, Solcia E, Ventura U. Freesoluble and outer membrane vesicle-associated VacA from Helicobacter pylori: Two forms of release, a different activity. Biochem Biophys Res Commun. 2005;337(1):173-8.

102. Winter J, Letley D, Rhead J, Atherton J, Robinson K. Helicobacter pylori membrane vesicles stimulate innate pro- and anti-inflammatory response and induce apoptosis in Jurkat T cells. Infect Immun. 2014;82:1372-81. https://doi.org/10.1128/IAl.01443-13.

103. Parker H, Keenan Jl. Composition and function of Helicobacter pylori outer membrane vesicles. Microbes Infect. 2012;14:9-16. https://doi.org/10.1016/j. micinf.2011.08.007.

104. Satin B, Del Giudice G, Della Bianca V, et al. The neutrophil-activating protein (HP-NAP) of Helicobacter pylori is a protective antigen and major virulence facto. J Exp Med. 2000;191:1467-76.

105. Unemo M, Aspholm-Hurtig M, Ilver D, et al. The sialic acid binding SabA adhesin of Helicobacter pylori is essential for nonopsonic activation of human neutrophils. J Biol Chem. 2005;280:15390-7. https://doi.org/10.1074/jbc.M412725200.

106. Ko SH, Jlk J, Kim YJ, et al. Helicobacter pylori outer membrane vesicle proteins induce human eosinophil degranulation via a $\beta 2$ integrin CD11/ CD18-and ICAM-1-dependent machanism. Mediat Inflamm. 2015;2015: 301716. https://doi.org/10.1155/2015/301716.

107. Suzuki N, Murata-Kamiya N, Yanagiya K, et al. Mutual reinforcement of inflammation and carcinogenesis by the Helicobacter pylori CagA oncoprotein. Sci Rep. 2015:5:10024. 10.1038 /serp10024.

108. Maeda S, Akanuma M, Mitsuno Y, et al. Distinct mechanisms of Helicobacter pylori-mediated NF-KB activation between gastric cancer cells and monocytic cells. J Biol Chem. 2001;276:44856-64. https://doi.org/10.1074/jbc. M105 381200.

109. Ismail S, Hampton MB, Keenan Jl. Helicobacter pylori outer membrane vesicles modulate proliferation and interleukin -8 production by gastric epithelial cells. Infect Immun. 2003;71:5670-5. https://doi.org/10.1128/IAl.71.10.5670-5675.2003.

110. Ko SH, Rho DJ, Jeon II, et al. Crude preparations of Helicobacter pylori outer membrane vesicles induce upregulation of heme oxygenase-1 via activating Akt-Nrf2 and mTOR-IKB kinase-NFKB pathways in dendritic cells. Infect Immun. 2016:84:2162-74. https://doi.org/10.1128/IAl.00190-16.

111. Toller IM, Neelsen KJ, Steger M, et al. Carcinogenic bacterial pathogen Helicobacter pylori triggers DNA double-strand breaks and a DNA damage response in its host cells. PNAS. 2011;108:14944-9. https:/doi.org/10.1073/ pnas.1100959108.

112. Hatakeyama M, Higashi H. Helicobacter pylori CagA: A new paradigm for bacterial carcinogenesis. Cancer Sci. 2005;96:835-43. https://doi.org/10.1111/ j.1349-7006.2005.00130.x.

113. Turkina MV, Olofsson A, Magnusson KE, Arnqvist A, Vikström E. Helicobacter pylori vesicles carrying CagA localize in the vicinity of cell-cell contacts and induce histone $\mathrm{H} 1$ binding to ATP in the epithelial cells. FEMS Microbiol Lett 2015;362: pii:fnv076; doi:https://doi.org/10.1093/femsle/ fnv076.

114. Choi HI, Choi JP, Seo J, et al. Helicobacter pylori-derived extracellular vesicles increased in the gastric juices of gastric adenosarcinoma patients and induced inflammation maliny via specific targeting of gastrin epithelial cells. Exp Mol Med. 2017;49:e330. https://doi.org/10.1038/emm.2017.47.

115. Chitcholtan K, Hampton MB, Keenan Jl. Outer membrane vesicles enhance the carcinogenic potential of Helicobacter pylori. Carcinogenesis. 2008;29: 2400-5. https://doi.org/10.1093/carcin/bgn218.

116. Shimoda A, Ueda K, Nishiumi S, et al. Exosomes as nanocarriers for systemic delivery of the Helicobacter pylori virulence factor CagA. Sci Rep. 2016;6: 18346. https://doi.org/10.1038/srep18346.

117. Mullaney E, Brown PA, Smith SM, Botting CH, Yamaoka YY, Terres AM, Kelleher DP, Windle HJ. Proteomic and functional characterization of the outer membrane vesicles from the gastric pathogen Helicobacter pylori. Proteomics Clin Appl. 2009;3(7):785-96. https://doi.org/10.1002/prca. 200800192.

118. Carlsohn, E., Nystrom, J., Karlsson, H., Svennerholm, A. M., Nilsson, C. L., Characterization of the outer membrane protein profile from disease-related Helicobacter pylori isolates by subcellular fractionation and nano-LC FT-ICR MS analysis. J Proteome Res. 2006, 5, 3197-3204.

119. Turner L, Bitto NJ, Steer DL, Lo C, D'Costa K, Ramm G, Shambrook M, Hill AF, Ferrero RL, Kaparakis-Liaskos M. Helicobacter pylori Outer Membrane Vesicle Size Determines Their Mechanisms of Host Cell Entry and Protein Content. Front Immunol. 2018 Jul 2;9:1466.

120. Cover TL, Krishna US, Israel DA, Peek RM Jr. Induction of gastric epithelial cell apoptosis by Helicobacter pylori vacuolating cytotoxin. Cancer Res. 2003;63:951-7.

121. Yamasaki E, Wada A, Kumatori A, et al. Helicobacter pylori vacuolating cytotoxin induces activation of the proapoptotic proteins Bax and Bak, leading to cytochrome c release and cell death. J Biol Chem. 2006;281: 11250-9. https://doi.org/10.1074/jbc.M509404200.

122. Yahiro K, Satoh M, Nakano M, et al. Low-density lipoprotein receptorrelated protein-1 (LRP1) mediates autophagy and apoptosis caused by Helicobacter pylori VacA. J Biol Chem. 2012;287:31104-5. https://doi.org/ 10.1074/jbc.M112.387498.

123. Yahiro K, Akazawa Y, Nakano M, et al. Helicobacter pylori VacA induces apoptosis by accumulation of connexin 43 in autophagic vesicles via a Rac1/ERK-dependent pathway. Cell Death Disc. 2015;1:1-15. https://doi.org/ 10.1038/cddiscovery.2015.35.

124. Neu B, Randlkofer $P$, Neuhofer $M$, et al. Helicobacter pylori induces apoptosis of rat gastric parietal cells. Am J Physiol-Gastrointest Liver Physiol. 2002;283: G309-80. https://doi.org/10.1152/ajpgi.00546.2001.

125. Rudi J, Kuck D, Strand S, et al. Involvement of the CD95 (APO-1/Fas) receptor and ligand system in Helicobacter pylori-induced gastric epithelial apoptosis. J Clin Invest. 1998;102:1506-14. https://doi.org/10.1172/JCI2808.

126. Wang J, Fan $X$, Lindholm C, et al. Helicobacter pylori modulates lymphoepithelial cell interactions leading to epithelial cell damage through Fas/Fas ligand interactions. Infect Immun. 2000;68:4303-11.

127. Fan X, Gunasena H, Cheng Z, et al. Helicobacter pylori urease binds to class II MHC on gastric epithelial cells and induces their apoptosis. J Immunol. 2000;165:1918-24

128. Ashktorab H, Dashwood RH, Dashwood MM, et al. H. pylori-induced apoptosis in human gastric cancer cells mediated via the release of apoptosis-inducing factor from mitochondria. Helicobacter. 2008;13:506-17. https://doi.org/10.1111/j.1523-5378.2008.00646.x.

129. Mohammadi M, Czinn S, Redline R, Nedrud. Helicobacter-specific cellmediated immune responses display a predominant Th1 phenotype and promote a delayed-type hypersensitivity response in the stomachs of mice. J Immunol. 1996;156:4729-38.

130. Miszczyk E, Walencka M, Rudnicka K, Matusiak A, Rudnicka W, Chmiela M. 2014. Antigen-specific lymphocyte proliferation as a marker of immune response in guinea pigs with sustained $H$. pylori infection. Acta Bioch Pol. 2014;61:295-303.

131. Muotiala A, Helander IM, Pyhälä L, Kosunen TU. Low biological activity of Helicobacter pylori lipopolysacharide. Infect Immun. 1992;60:1714-6.

132. Semeraro N, Montemurro P, Piccoli C, et al. Effect of Helicobacter pylori Lipopolysaccharide (LPS) and LPS derivatives on the production of tissue factor and plasminogen activator inhibitor type 2 by human blood mononuclear cells. J Infect Dis. 1996;174:1255-60.

133. Bachmann MF, Jennings GT. Vaccine delivery: A matter of size, geometry, kinetics and molecular patterns. Nat Rev Immunol. 2010; 10:787-96.

134. Mashburn-Warren LM, Whiteley M. Special delivery: Vesicle trafficking in prokaryotes. Mol Microbiol. 2006;61:839-46.

135. Leo van der Pol, Michiel Stork, Peter van der Ley. Outer membrane vesicles as platform vaccine technology. Biotechnol J. 2015 Sep; 10(11): 1689-1706. Published online 2015 Nov 11. doi: https://doi. org/10.1002/biot.201400395

136. Mnich E, Kowalewicz-Kulbat M, Sicinska P, et al. Impact of Helicobacter pylori on the healing process of the gastrin barrier. World J Gastroenterol. 2016;22: 7536-58. https://doi.org/10.3748/wjg.v22.i33.7536.

137. Shimoda A, Ueda K, Nishiumi S, Murata-Kamiya N, Mukai S, Sawada S, Azuma T, Hatakeyama M, Akiyoshi K. Exosomes as nanocarriers for systemic delivery of the Helicobacter pylori virulence factor. CagA Sci Rep. 2016;6:18346. 
138. Fassan M, Saraggi D, Balsamo L, Cascione L, Castoro C, Coati I, De Bernard M, Farinati F, Guzzardo V, Valeri N, Zambon CF, Rugge M. Let-7c downregulation in Helicobacter pylori-related gastric carcinogenesis Oncotarget. $2016 \operatorname{Jan} 26$; 7(4): 4915-4924. Published online 201; 17. doi: https://doi.org/ 10.18632/oncotarget.6642

139. Chmiela M, Gajewski A, Rudnicka K. Helicobacter pylori vs coronary heart disease - searching for connections. World I Gastroenterol. 2015;7:187-203. https://doi.org/10.4330/wjc.v7.i4.187.

140. Chmiela M, Gonciarz W. Molecular mimicry in Helicobacter pylori infections. World J Gastroenterol. 2017;23:3964-77.

Ready to submit your research? Choose BMC and benefit from:

- fast, convenient online submission

- thorough peer review by experienced researchers in your field

- rapid publication on acceptance

- support for research data, including large and complex data types

- gold Open Access which fosters wider collaboration and increased citations

- maximum visibility for your research: over $100 \mathrm{M}$ website views per year

At $\mathrm{BMC}$, research is always in progress.

Learn more biomedcentral.com/submissions 